\title{
Sulphur Deficiency Causes a Reduction in Antimicrobial Potential and Leads to Increased Disease Susceptibility of Oilseed Rape
}

\author{
P.-H. Dubuis ${ }^{1}$, C. Marazzi ${ }^{2}$, E. Städler ${ }^{2}$ and F. Mauch ${ }^{1}$ \\ Authors' addresses: ${ }^{1}$ Department of Biology, University of Fribourg, Pérolles, 1700 Fribourg, Switzerland; \\ ${ }^{2}$ Eidg. Forschungsanstalt, Postfach 185, CH-8820 Wädenswil, Switzerland (correspondence to F. Mauch. \\ E-mail: felix.mauch@unifr.ch) \\ Received June 17, 2004; accepted November 1, 2004
}

Keywords: disease resistance, glucosinolate, phytoanticipin

\begin{abstract}
The reduction of atmospheric sulphur dioxide pollution is causing increasing problems of sulphur deficiency in sulphur-demanding crop plants in northern Europe. Elemental sulphur and many sulphur containing compounds such as cysteine-rich antifungal proteins, glucosinolates (GSL) and phytoalexins play important roles in plant disease resistance. The aim of this work was to analyse the effect of inadequate sulphur supply on disease resistance of oilseed rape (Brassica napus). Compared with fertilized oilseed rape, healthy looking S-deficient plants showed increased susceptibility to the blackleg fungus Leptosphaeria maculans, to the generalist necrotroph Botrytis cinerea and to the oomycete Phytophthora brassicae. To analyse possible causes of the increased disease susceptibility of S-deficient plants, protein extracts and methanolic extracts of secondary metabolites of plants grown with and without adequate sulphur supply were tested for antimicrobial activity. None of the protein extracts showed antimicrobial activity. However, extracts containing secondary metabolites from normally grown plants showed a strong antimicrobial activity in in vitro tests with various fungal and bacterial pathogens. This activity was almost totally lost in extracts derived from S-deficient plants. The antimicrobial activity did not appear to be based on the activity of phytoalexins because it was present in healthy plants and was not increased by a previous inoculation with Botrytis cinerea. The loss of antifungal activity in S-deficient plants correlated with a strong reduction of various GSL, thus suggesting a reduced level of GSL as a possible cause of the reduced antimicrobial potential. However, limited tests of commercially available GSL or their degradation products did not demonstrate a causal link. Our results show that S-deficiency of oilseed rape negatively affects disease resistance and suggest that this effect is at least
\end{abstract}

partially caused by a reduction of sulphur-dependent phytoanticipins.

\section{Introduction}

Sulphur is an essential macroelement for plant life and has numerous biological functions (Leustek et al., 2000). It is taken up by plants in its inorganic sulphate form from the soil or as sulphur dioxide and hydrogen sulphide from the atmosphere. Plants assimilate and reduce sulphate to sulphide which is incorporated into cysteine and further converted to methionine. Sulphurcontaining compounds play crucial roles in a number of cellular processes, such as redox reactions, detoxification of heavy metals and xenobiotics, and metabolism of secondary products (Saito, 2000; Nikiforova et al., 2003).

Intensive farming has greatly increased the demand for sulphur in crop production in the last decades. This development was largely unnoticed in industrialized countries because of concomitant pollution by atmospheric deposition of sulphur dioxide produced by the burning of S-containing fossil fuels. In the second part of the 20th century air pollution with sulphur dioxide became a major concern (http://www.ourplanet. com). In response to this global problem governments started to enforce a drastic reduction of sulphur dioxide emissions (Helsinki Protocol, 1979). As an unexpected outcome of the successful reduction of S-pollution an increased frequency of sulphur deficiency was to be observed in several crops mainly in northern Europe. Inadequate sulphur supply was becoming a factor limiting crop yield and quality (Dämmgen et al., 1998; Eriksen and Mortensen, 1999).

It has been known since antiquity that sulphur has protective effects against pests and diseases. Most of the knowledge is however restricted to the external effect of foliar applied inorganic sulphur. Less is known about soil supplied sulphur which has a strong influence on 
plant resistance by directly stimulating biochemical processes in primary and secondary metabolism (Pezet et al., 1986; Schnug, 1996). Field observations pointed to a positive correlation between S-fertilization and enhanced disease resistance against fungal pathogens, leading to the question, whether sulphate availability could be a limiting factor for the ability of plants to fight off pathogens (Davidson and Goss, 1972; Schnug, 1996). Many compounds that play a role in active defence against pathogens contain sulphur including cysteine-rich antifungal peptides, phytoalexins and glucosinolates (GSL) (Hell, 1997; Pedras et al., 2000). In addition, elemental sulphur $\left(\mathrm{S}^{0}\right)$ has been described as a component of disease resistance in certain plant species (Williams and Cooper, 2003, 2004).

In recent years oilseed rape (Brassica napus L.) has become a major crop in Europe and one of the major oil crops worldwide (Graner et al., 2003). Because of its high demand for sulphur, oilseed rape is particularly sensitive to S-deficiency. It produces seeds with a high content of sulphur rich proteins (Zhao et al., 1997; Blake-Kalff et al., 1998) and requires sulphur for the synthesis of GSL, a group of thioglucoside compounds (Blake-Kalff et al., 1998), and S-containing phytoalexins (Hammerschmidt and Dann, 1999).

We have analysed the effect of inadequate S-supply on the resistance of oilseed rape to different pathogens. Of the phytopathogenic fungi known to affect oilseed rape, the ascomycete fungus Leptosphaeria maculans (anamorph: Phoma lingam) causes the highest economic losses worldwide (Howlett et al., 2001). Leptosphaeria maculans is a specific pathogen of Brassica species and is a facultative necrotroph initially growing biotrophically and later promoting necrosis to live saprophytically on dead plant material (Hammond et al., 1985; Hammond and Lewis, 1987). Phytophthora brassicae is an hemibiotrophic oomycete which is able to infect a wide range of Crucifer species including B. napus and Arabidopsis thaliana (Man in't Veld et al., 2002; Si-Ammour et al., 2003). Botrytis cinerea (teleomorph Botryotinia fuckeliana), commonly named grey mould, is a necrotrophic pathogen with a broad host range (MacFarlane, 1968). It was chosen as a nonspecialized ubiquitous pathogen for comparison with the specialized L. maculans. Our results show a clear effect of the S-nutritional status of the plant on its disease resistance against all three pathogens. The reduced disease resistance of S-deficient plants correlated with a strong reduction of antimicrobial activity of plant extracts and a greatly reduced content of various GSL.

\section{Materials and Methods}

Organisms and growth conditions

Seeds of Brassica napus cv. Bienvenu (0) and cv. Express (00) were obtained from the Swiss Federal Agricultural Research Station of Plant Production in Changins. Seeds were sown on vermiculite and watered first with tap water and after 10 days once with half strength Hoagland solution containing $0.5 \mathrm{mM} \mathrm{MgSO}_{4}$ (Hoagland and Martin, 1950). After 15 days the seed- lings were transferred to pots (diameter $12 \mathrm{~cm}$ ) containing quartz sand and further watered with $0.5 \times$ Hoagland solution with or without addition of $0.5 \mathrm{~mm}$ $\mathrm{MgSO}_{4}$. For the S-deficient plants the $\mathrm{MgSO}_{4}$ was replaced by equimolar amount of $\mathrm{MgCl}_{2}$, and among micronutrients $\mathrm{CuCl}_{2}, \mathrm{MnCl}_{2}$ and $\mathrm{ZnCl}_{2}$ were used instead of $\mathrm{CuSO}_{4}, \mathrm{MnSO}_{4}$ and $\mathrm{ZnSO}_{4}$. Plants were grown in a growth chamber with $20^{\circ} \mathrm{C}, 16 \mathrm{~h}$ light/ $18^{\circ} \mathrm{C}, 8 \mathrm{~h}$ dark cycle. Plants were used for experiments 5-6 weeks after planting which corresponded to a period of 3-4 weeks of sulphur starvation.

Leptosphaeria maculans (anamorph: Phoma lingam), Penicillium digitatum and Cladosporium sp. isolates were obtained from the Swiss Federal Agricultural Research Station of Plant Production in Changins and grown on potato dextrose agar (PDA; Difco, Detroit, MI, USA) containing $25 \mu \mathrm{g} / \mathrm{ml}$ of aureomycin (chlortetracycline hydrochloride; Rectolab SA, Servion, Switzerland). Leptosphaeria maculans pycnidiospore production was induced by growing colonies for 14 days at $15^{\circ} \mathrm{C}$ under a $12 \mathrm{~h}$ black light (OSRAM L3673 BLB)/12 h dark cycle. Pycnidiospores were harvested according to Hammond et al. (1985). The Botrytis cinerea isolates BMM (Zimmerli et al., 2001) and Pellier were isolated respectively from geranium and vine and grown on PDA. Conidia from 14-day old well-sporulating colonies were harvested in distilled water containing $0.2 \%$ (v/v) Tween 20. The oomycete $P$. brassicae constitutively expressing a green fluorescent protein (GFP) was grown on V8 agar (Si-Ammour et al., 2003). Pseudomonas syringae pv. tomato strain DC3000 (PstDC3000) was grown in Luria broth with $25 \mu \mathrm{g} / \mathrm{ml}$ rifampicin.

\section{Inoculation protocols}

Leaves of 5-6-week-old plants, at growth stage 2.4-2.5 of the scale according to Harper and Berkenkamp (1975), were inoculated with the different pathogens. For Leptosphaeria maculans $10 \mu \mathrm{l}$ of a spore suspension $\left(10^{6}\right.$ spores $\left./ \mathrm{ml}\right)$ in water containing $0.2 \%(\mathrm{v} / \mathrm{v})$ Tween 20 was applied to the leaves after wounding with a needle. Plants were incubated for 5 days in $100 \%$ relative humidity in a glass chamber before the lids were removed. Lesion size was measured at 12 and/or $21 \mathrm{dpi}$. For Botrytis cinerea $10 \mu \mathrm{l}$ of a spore suspension $\left(10^{4}\right.$ spores $\left./ \mathrm{ml}\right)$ in water containing $0.2 \%$ (v/v) Tween 20 was applied to the leaves after wounding with a needle. Plants were incubated at 100\% relative humidity and lesion size was measured at 4 or 5 dpi. Agar plugs taken from the margins of an expanding colony of $P$. brassicae isolate $\mathrm{HH}$ (SiAmmour et al., 2003) were applied to the leaves after wounding with a needle. Plants were then incubated in $100 \%$ relative humidity for 7 days for lesion size measurement. GFP fluorescence was determined 4 days after the inoculation (Si-Ammour et al., 2003).

\section{Measurements of total sulphur and glutathione}

For total S content, leaves of 6-week-old B. napus cv. Bienvenu plants were dried for $48 \mathrm{~h}$ at $65^{\circ} \mathrm{C}$ and then 
ground to a fine powder. Two independent batches of plants were mixed for analysis. Total $\mathrm{S}$ was determined using a Philips PW2400 X-ray fluorescence (X-RF) spectrometer (Philips, Almelo, The Netherlands) under constant helium flux (Schnug and Haneklaus, 1992). Total glutathione (GSH) content of 6-week-old $B$. napus plants cv. Bienvenu was determined according to Harms et al. (2000). Frozen leaf material $(60 \mathrm{mg}$ ) was homogenized to a fine powder and extracted for $15 \mathrm{~min}$ in $600 \mu \mathrm{l} 0.1 \mathrm{~N} \mathrm{HCl}$ at $4^{\circ} \mathrm{C}$. After centrifugation $\left(20 \mathrm{~min}, 14000 \times \mathrm{g}, 4^{\circ} \mathrm{C}\right), 120 \mu \mathrm{l}$ of the supernatant were added to $200 \mu \mathrm{l}$ of $0.2 \mathrm{M} 2$-(cyclohexylamino) ethanesulphonic acid (pH 9.3). Reduction of total disulphides was performed by adding $10 \mu 19 \mathrm{~mm}$ bis2-mercaptoethylsulphone in $200 \mathrm{~mm}$ Tris- $\mathrm{HCl}$ and $5 \mathrm{~mm}$ EDTA (pH 8). After $40 \mathrm{~min}$ at room temperature, free thiols were labelled with $20 \mu \mathrm{l}$ of $15 \mathrm{~mm}$ monobromobimane in acetonitrile and incubated for $15 \mathrm{~min}$ in the dark at room temperature. The reaction was stopped by adding $250 \mu 115 \% \mathrm{HCl}$. The samples were analysed by high-performance liquid chromatography (HPLC) (Harms et al., 2000).

\section{Plant extractions and glucosinolate analysis}

Methanol extracts of leaves (Griffiths et al., 2001) were used for fungal and bacterial in vitro growth inhibition tests and to quantify the content of GSL. For glucosinolate determination, $20 \mu \mathrm{l}$ aliquots, were analysed by HPLC. The analytical column was equipped with a Lichrospher (Marchery and Nagel, Oensingen, Switzerland) $(100 \mathrm{RP} 18 ; 5 \mu \mathrm{m}, 4 \times 250 \mathrm{~mm})$. The binary mobile phase system was composed of distilled water (A) and water : acetonitrile, $80: 20$ (B). The analysis was run with the following gradient programme: 0-45 min linear gradient $0-100 \% \mathrm{~B}$ and then held for $5 \mathrm{~min}$ on $100 \% \mathrm{~B}$. The flow rate was $1 \mathrm{ml} / \mathrm{min}$ and the detection of desulphoglucosinolates was monitored with a UV/VIS detector at $230 \mathrm{~nm}$ (Contron HPLC detector 430, Contron, Zürich, Switzerland). For test of antimicrobial activity methanol extracts from $10 \mathrm{~g}$ of leaves were evaporated to dryness and the remaining material was taken up in $10 \mathrm{ml}$ of water. For bioassay with methanol extracts of plants after induction of defence mechanisms, detached leaves of 6-week-old plants were inoculated with Botrytis cinerea at a concentration of $3 \times 10^{3}$ spores $/ \mathrm{ml}$. After $60 \mathrm{~h}$ the leaves were extracted as described above. For protein extraction leaves were ground in liquid nitrogen with a mortar and pestle. The resulting powder $(5 \mathrm{~g})$ was extracted with 2.5 volume of $50 \mathrm{~mm}$ Tris- $\mathrm{HCl}$ pH 7.5 containing $1 \mathrm{~mm}$ phenylmethylsulphonyl fluoride. Insoluble material was removed by centrifugation at $10000 \times \boldsymbol{g}$ for $20 \mathrm{~min}$. Proteins in the supernatant were precipitated with ammonium sulphate ( $95 \%$ saturation) at $0^{\circ} \mathrm{C}$ for $2 \mathrm{~h}$, collected by centrifugation $(20000 \times \boldsymbol{g}$, $20 \mathrm{~min}$ ) and resuspended in $2 \mathrm{ml} 10 \mathrm{~mm}$ Tris- $\mathrm{HCl}$ $\mathrm{pH}$ 7.5. The extracts were desalted using Sephadex G-25 columns (Amersham Biosciences, Otelfingen, Switzerland) and filtered successively through 0.45 and $0.22 \mu \mathrm{m}$ membranes prior to application in the bioassays.
Bioassays for antimicrobial activity

Fungal spores harvested from well-sporulating colonies of L. maculans and Botrytis cinerea grown on PDA plates were resuspended in half-strength potato dextrose broth (Difco, Detroit, MI, USA). The concentration of the spore suspensions was adjusted to $2-4 \times 10^{5}$ spores $/ \mathrm{ml}$. The freshly prepared spore suspensions were spread on $9 \mathrm{~cm}$ Petri dishes containing PDA $(0.5 \mathrm{ml} / \mathrm{dish})$. The plates were incubated $24 \mathrm{~h}$ at $18^{\circ} \mathrm{C}$ to allow the spores to germinate. At this time, $5 \mathrm{~mm}$ diameter sterile paper filter discs were laid on the agar surface and $40 \mu \mathrm{l}$ of the solution to be tested was applied to the discs. After an additional 48-72 h incubation at $18^{\circ} \mathrm{C}$ the inhibition zones were measured and pictures were taken. For each treatment three repetitions with five replicates were carried out with two independent extracts. For pure molecule bioassays $40 \mu \mathrm{l}$ of isothiocyanate (ITC; Fluka, Buchs, Switzerland) at concentrations of $1 \mathrm{~mm}$ and $10 \mu \mathrm{M}$ were applied to Petri dishes with Cladosporium sp. For sinigrin degradation products $10 \mathrm{~mm}$ sinigrin (Carl Roth AG, Karlsruhe, Germany) in $0.33 \mathrm{M}$ potassium phosphate buffer was incubated with 5 units myrosinase (thioglucoside glucohydrolase; Sigma Chemicals, St Louis, MO, USA) for $1 \mathrm{~h}$ at $37^{\circ} \mathrm{C}$. Pathogen growth inhibition tests in microtitre plates were performed as described (Berrocal-Lobo et al., 2002).

\section{Results}

In the field sulphur-starved plants often show only weak or no visible symptoms during vegetative growth but the effect of S-deficiency on yield and disease resistance can be nonetheless important. Three to four weeks after the onset of sulphur starvation, at the time of pathogen inoculation, the S-starved plants did not show any visible signs of S-deficiency. At this time point plants grown on full nutritive solution (Fig. 1a) could not be distinguished from S-deficient plants (Fig. 1b). However, when the plants were starved for four more weeks younger leaves started to exhibit strong S-deficiency symptoms (Fig. 1c). The typical chlorosis spread over intercostal areas with anthocyan accumulation but leaving the zones along the veins green (Haneklaus and Schnug, 1992).

To confirm that S-starved plants had a lower S-content, total sulphur and GSH was measured at the time of inoculation (Table 1). Six-week-old B. napus plants that were S-starved for 4 weeks contained only approximately $10 \%$ of the total sulphur and $6 \%$ of GSH compared with normally fertilized plants. Plants grown on soil were included in our analysis to test if the culturing system reproduced the sulphur status of plants growing under normal conditions. Oilseed rape plants grown on sulphur containing Hoagland solution showed approximately $20 \%$ reduction in total sulphur and a $60 \%$ reduction in total GSH content relative to soil grown plants. With the X-RF analysis method used to determine total sulphur content it was possible to also obtain the plant content for $\mathrm{Fe}, \mathrm{Ca}, \mathrm{Mg}, \mathrm{K}$ and $\mathrm{P}$. We observed no significant difference for $\mathrm{Ca}$, 

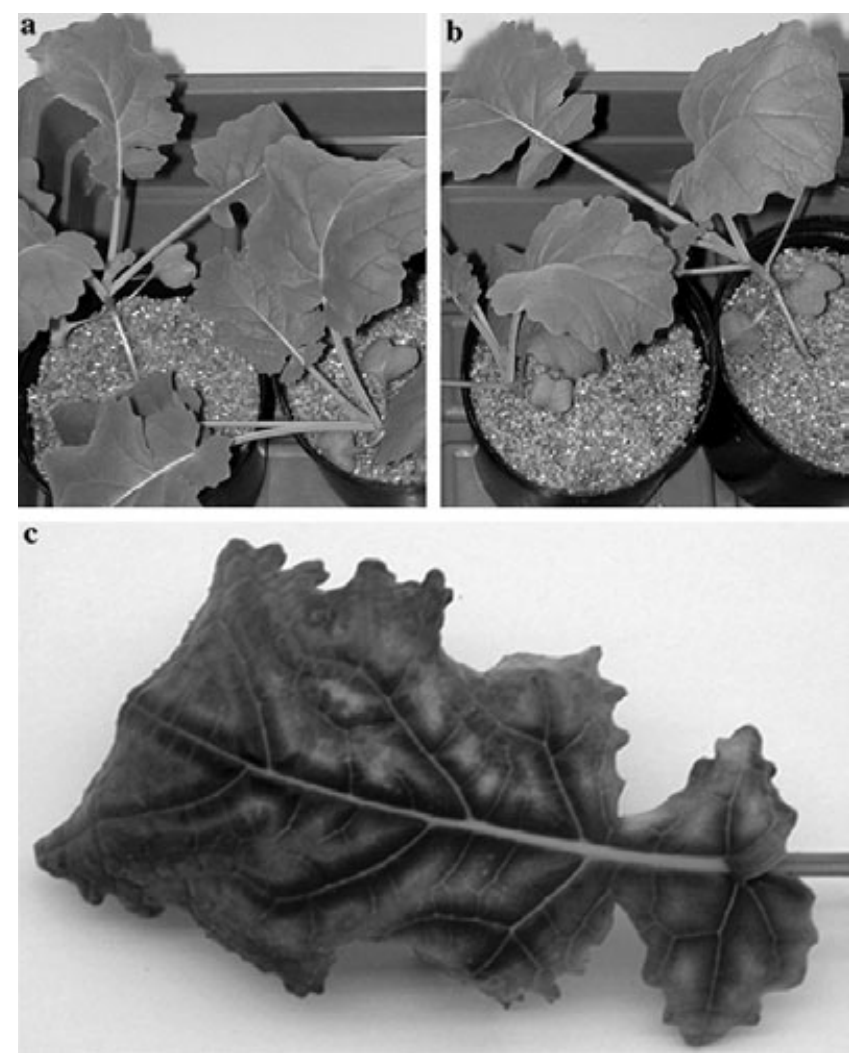

Fig. 1 Growth phenotype of S-deficient Brassica napus cv. Express. (a) Six-week-old $B$. napus plants grown on quartz sand fertilized with Hoagland solution containing $\mathrm{MgSO}_{4}$ and (b) without sulphate fertilization. No S-deficiency symptoms were visible 4 weeks after the onset of S-starvation. (c) After 8 weeks of S-starvation plants showed clear symptoms of S-deficiency

Table 1

Total sulphur (S) and glutathione (GSH) content of leaves of six week old Brassica napus plants grown on soil or on quartz sand with $(+\mathrm{S})$ or without $(-\mathrm{S}) \mathrm{S}$-fertilization. The S-deficient plants did not receive sulphur fertilization for 4 weeks

\begin{tabular}{lcc}
\hline & \multicolumn{2}{c}{ B. napus cv. Bienvenu } \\
\cline { 2 - 3 } & $\begin{array}{c}\text { Total S } \\
(\% \text { of } \mathrm{DW})\end{array}$ & $\begin{array}{c}\text { GSH total } \\
(\mathrm{nmol} / \mathrm{g} \mathrm{FW} \pm \mathrm{SE})\end{array}$ \\
\hline Soil & 1.30 & $140.0 \pm 18.3$ \\
Sand/Hoagland $+\mathrm{S}$ & 1.02 & $59.1 \pm 7.5$ \\
Sand/Hoagland $-\mathrm{S}$ & 0.10 & $3.7 \pm 1.0$ \\
\hline
\end{tabular}

$\mathrm{Mg}$ and P. Potassium was reduced in sulphur-starved plants by approximately $40 \%$ and $\mathrm{Fe}$ was below detection level in all samples (data not shown).

Three pathogen species were used to study the effect of inadequate sulphur nutrition on plant disease resistance: L. maculans, Botrytis cinerea and P. brassicae. Five different isolates of $L$. maculans and two isolates of Botrytis cinerea exhibiting different levels of aggressiveness were screened to find for both pathogens a moderately aggressive isolate that could show enhanced disease symptoms on sulphur-deficient plants. Brassica napus cultivar Bienvenu was challenged with both L. maculans and Botrytis cinerea. Because of the high resistance level to L. maculans cul- tivar Express was only infected with Botrytis cinerea. Figure 2a shows typical lesions triggered by each pathogen on leaves of B. napus grown with and without sulphur fertilization. For all three pathogens lesion size is clearly affected by the sulphur status of the plant. With both L. maculans and Botrytis cinerea on control plants the necrotic lesions were surrounded by a dark circle which clearly defined the edge of the lesion. In S-starved plants this dark circle was missing and the lesion expanded broadly. Figure $2 \mathrm{~b}$ shows a quantitative analysis of the effect of the sulphur status of B. napus cv. Express and/or cv. Bienvenu on disease susceptibility against the three pathogens. At 21 days postinoculation (dpi) lesions caused by L. maculans on S-starved B. napus cv. Bienvenu leaves were 1.9 times larger than in normally fertilized plants. In control plants lesion size remained the same between $12 \mathrm{dpi}$ and $21 \mathrm{dpi}$ whereas it continued to increase in S-starved plants (data not shown). More pronounced differences were observed with Botrytis cinerea in both $B$. napus cv. Express and cv. Bienvenu. In the cultivar Express, at $4 \mathrm{dpi}$, lesions were 24 times larger in sulphur starved plants compared with the controls. In the cultivar Bienvenu this increase was only 3.7-fold. Finally, compared with control plants the lesions caused by $P$. brassicae were 3.3 times larger in plants lacking adequate S-nutrition.

To quantify pathogen development by another method, an isolate of $P$. brassicae was used that constitutively expressed GFP as a quantitative marker (Si-Ammour et al., 2003). This fluorescent isolate allowed to quantify the pathogen biomass by measuring GFP fluorescence. Figure 3 shows that uninfected leaves (black area) had a baseline fluorescence because of chlorophyll autofluorescence of 467 relative units (ru) for the control plants and $317 \mathrm{ru}$ for the S-starved plants. The fluorescence level was only slightly increased to $644 \mathrm{ru}$ in control plants inoculated with $P$. brassicae expressing GFP indicating that the pathogen did hardly colonize these plants. In contrast, in inoculated S-starved plants the fluorescence increased to $1172 \mathrm{ru}$. After subtraction of the background fluorescence there was a 4.8 fold increase in GFP fluorescence levels between normally fertilized and S-starved plants. Thus, the pathogen development measured by the GFP fluorescence showed increased biomass in plants grown under sulphur starvation conditions.

Our results demonstrate that S-deficiency negatively affects disease resistance of $B$. napus. The increase in susceptibility could be caused by the specific effect of S-starvation on the accumulation of one or more S-containing defence compounds. To further analyse this hypothesis, extracts of normal and S-deficient plants were tested for their antifungal potential in in vitro growth inhibition assays. To isolate various secondary compounds leaves were extracted with hot methanol (see Material and Methods). After evaporation to dryness and resuspension in water $(1 \mathrm{ml} / \mathrm{g}$ leaf material), the extracted compounds from control plants were found to inhibit the in vitro growth of 


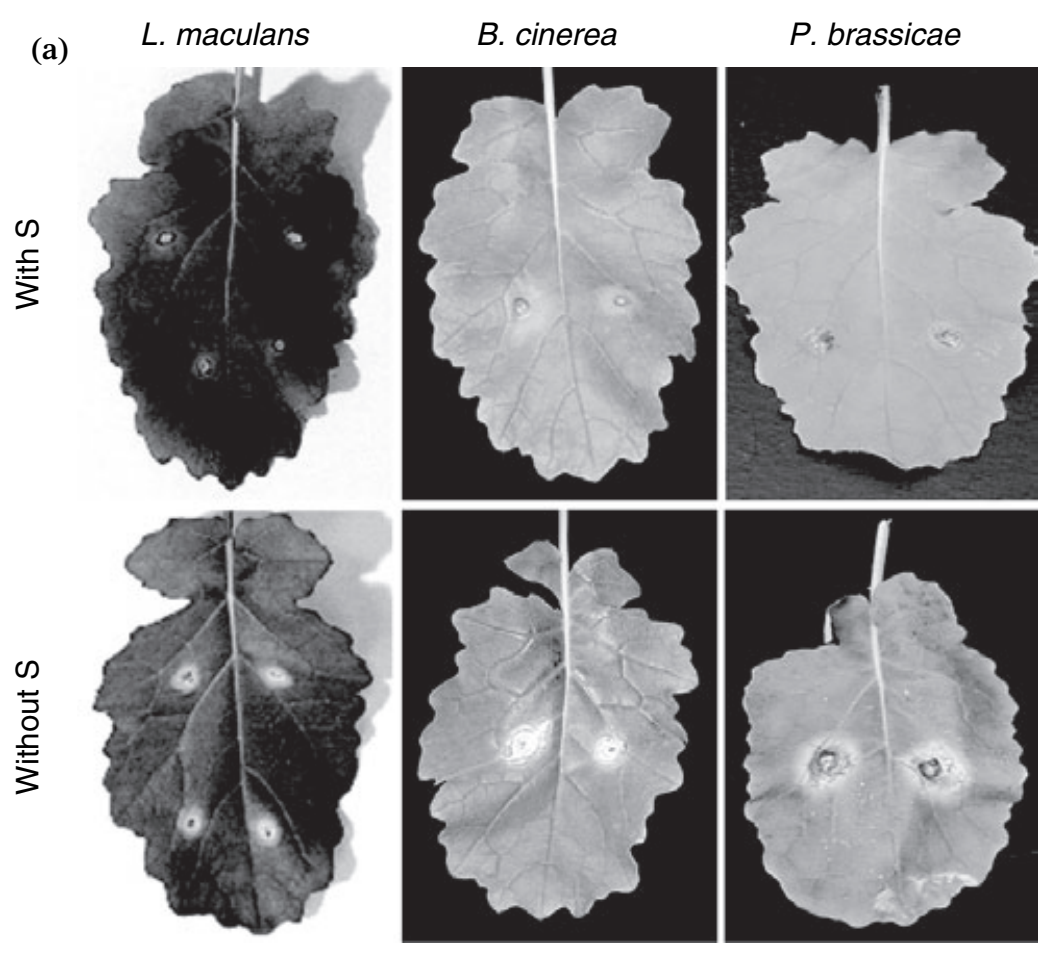

Fig. 2 Disease resistance tests of normal and S-deficient Brassica napus plants. (a) Disease symptoms on leaves B. napus caused by inoculation with Leptosphaeria maculans (21 dpi), Botrytis cinerea (4 dpi) and Phytophthora brassicae (7 dpi). The plants were 6 weeks old at the time of inoculation and were S-starved for 4 weeks (without S) or normally fertilized (with S). (b) Quantitative analysis of the lesions size measurements. The experiments were repeated three times. Thirty-two independent measurements were performed for L. maculans. Sixteen independent measurements were performed for Botrytis cinerea and P. brassicae respectively

(b)

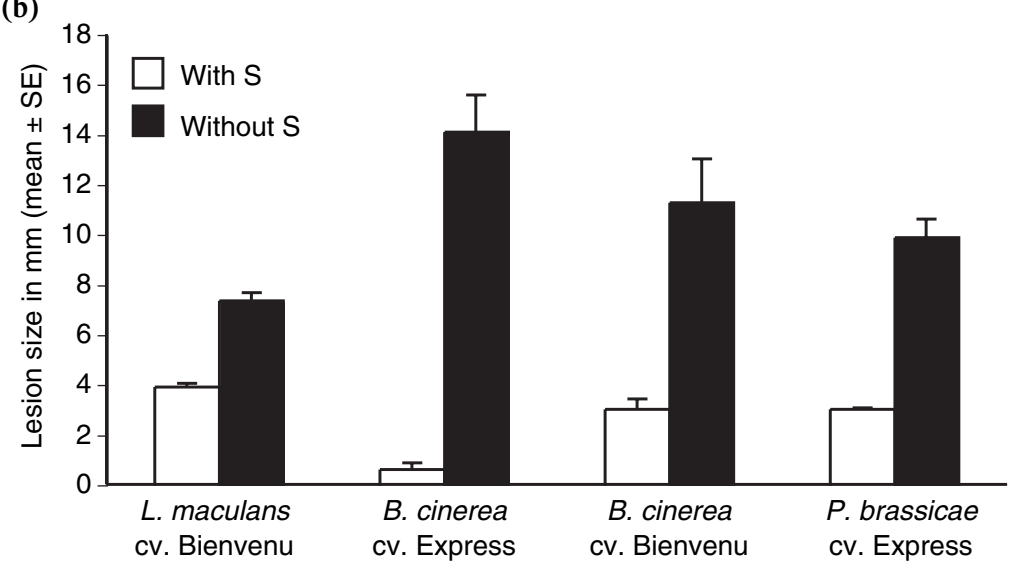

the four fungal pathogens L. maculans, Botrytis cinerea, Cladosporium sp. and Penicillium digitatum as indicated by the growth inhibition zones around the applied extract (Fig. 4a). A similar extract from plants suffering S-deficiency had no or very little effect on all four pathogens tested. Figure $4 \mathrm{~b}$ shows that the inhibition zones caused by extracts from S-fertilized plants were in comparison with S-deficient plants 6.6 times larger for L. maculans, 6.8 times larger for Botrytis cinerea, 12 times larger for Cladosporium sp. and 25 times larger for Penicillium digitatum. Figure 4c shows the effect of the methanol extracted compounds on the growth of the phytopathogenic bacterium Pseudomonas syringae pv. tomato, of Botrytis cinerea and of Penicillium digitatum assayed in liquid culture in microtitre plates. Pathogen growth was measured as an increase in absorbance at $490 \mathrm{~nm}$. Methanol extracted compounds from S-deficient plants had 5.4 times lower antibacterial activity than extracts from control plants.
The reduction in antifungal potential was 2.2-fold for Botrytis cinerea and 2.5-fold for Penicillium digitatum.

To test if the antifungal potential was increased following inoculation because of induced metabolites, methanol extracts of Botrytis cinerea inoculated $B$. napus leaves were analysed in fungal growth inhibition test. Figure 5 shows no significant difference in antifungal potential between extracts of inoculated or control plants leading to the conclusion that the antifungal potential is because of phytoanticipins and not phytoalexins. Furthermore, no inhibition was observed with protein extracts from both control and S-starved plants, challenged or not with a previous inoculation by Botrytis cinerea.

The methanolic extracts were analysed for GSL. Table 2 shows a list of the 11 different GSL analysed, the group to which they belong and the GSL levels measured in nomal and S-deficient plants. The level of each individual GSL was dramatically reduced in 


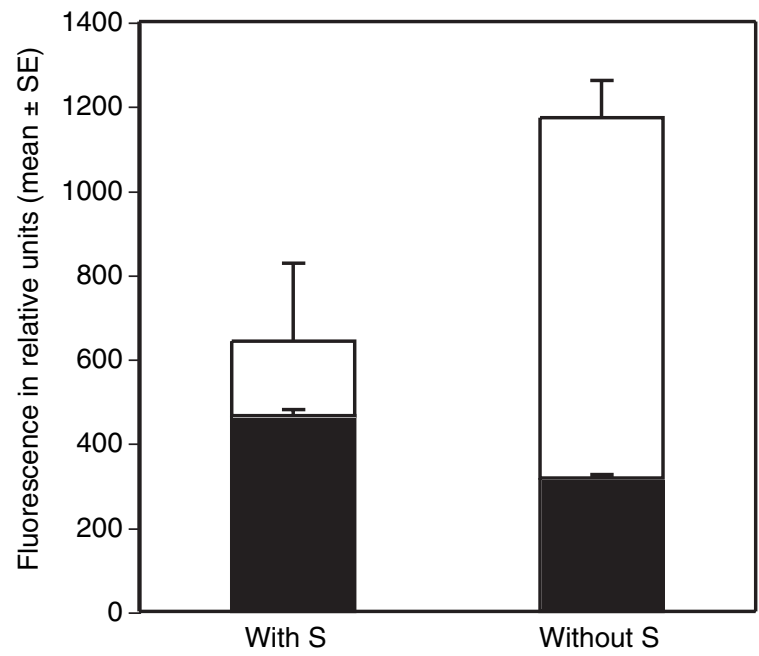

Fig. 3 GFP fluorescence of differently fertilized Brassica napus cv. Express infected with Phytophthora brassicae constitutively expressing GFP. Black area of columns shows the level of chlorophyll autofluoresence. White area shows the GFP fluorescence caused by the spread of $P$. brassicae. Leaf patches of $5 \mathrm{~mm}$ diameter were analysed

S-deficient plants. Figure 6 shows the quantification of the grouped GSL. The reduction of GSL content in S-deficient plants was 14 times for indolyl GSL, 18 times for aromatic GSL, 21 times for thioalkyl GSL and 85 times for alkene GSL. Thus, S-deficiency had a dramatic negative effect on the glucosinolate content. There was a good correlation between reduced GSL levels and reduced antimicrobial activity of the GSL containing methanol extract. To test the hypothesis that GSL could be responsible for the antifungal potential, eight different commercially available ITC were tested for their antifungal potential on agar plates against Cladosporium (Table 3). None of the eight ITC nor degradation products of sinigrin showed antifungal activity even at a high concentration of $1 \mathrm{~mm}$ (data not shown). It remains therefore an open question whether the reduced content of some GSL was causing the reduction in antimicrobial activity in S-deficient plants. It is still possible that a combination of GSL or degradation products of the many additional GSL of B. napus possess direct antifungal activity.

\section{Discussion}

The response of plants to pathogen includes the production of a number of S-containing compounds such as the phytoalexins and GSL of crucifers or sulphur rich antifungal peptides (Vignutelli et al., 1998; Tierens et al., 2001). The reduction of atmospheric sulphur pollution achieved in the last decades caused S-deficiency in the field and had a negative impact on yield, product quality and pathogen resistance. In this study we focused on the effect of S-deficiency on plant disease resistance.

Taken together our results demonstrate that oilseed rape grown under S-deficiency conditions exhibited enhanced disease susceptibility (Fig. 2). This was true for the two tested B. napus cultivars Express and Bien- venu and for all pathogens tested, for the specialized L. maculans and P. brassicae as well as for the ubiquitous pathogen Botrytis cinerea. The enhanced disease susceptibility is apparently caused by a general mechanism because the change in susceptibility was not pathogen or cultivar specific. Field experiments pointed at a positive correlation between S-fertilization and disease resistance of oilseed rape against fungal pathogens but no causal link was demonstrated (Schnug, 1996). There are two main arguments to explain why S-deficient plants become more susceptible to pathogens. First, the increased susceptibility is caused by the specific effect of S-deficiency on the accumulation of S-containing defence compounds such as phytoalexins, GSL and cysteine-rich antifungal polypeptides which can play important roles in disease resistance. Secondly, S-deficiency leads to a general reduction of fitness and a global weakening of the plant that causes generally enhanced susceptibility to stress.

In our study, extracts of secondary compounds from control plants showed antifungal activity with four different fungal pathogens and this activity was almost completely lost in S-deficient plants (Fig. 4). It is important to note that the extracted compounds were not concentrated during the processing prior to the tests. The concentration tested (ratio $1 \mathrm{ml} / \mathrm{g}$ leaf tissue) was similar to the concentration present in the leaf tissue. The antifungal potential was not increased by activation of induced defence mechanism (Fig. 5). The antimicrobial compounds apparently belong to the phytoanticipins present in healthy plants before infection and not to the phytoalexins which accumulate upon infection. Interestingly, the reduced antifungal activity of extracts from S-deficient plants correlated with a strong reduction in GSL content. Upon tissue damage GSL come in contact with the enzyme myrosinase (thioglucoside glucohydrolase, EC 3.2.3.1) and the unstable aglycone generated by the action of myrosinase may then form various degradation products, including ITC, nitriles and thiocyanates, all of which are highly reactive compounds (Mithen et al., 1986; Osbourn, 1996). The major breakdown products generated in leaves of Brassica are ITCs. GSL hydrolysis products have been demonstrated to be toxic towards a range of fungi in vitro, including pathogens and nonpathogens of Brassica. The precise mechanism of toxicity is however not known (Mari et al., 1993; Manici et al., 1997; Hashem and Saleh, 1999). A number of pathogens of Brassica, such as L. maculans (Mithen et al., 1986), Peronospora parasitica (Greenhalgh and Mitchell, 1976), Mycosphaerella brassicae (Hartill and Sutton, 1980) and Alternaria sp. (Milford et al., 1989) have been shown to be sensitive to at least some glucosinolate breakdown products. It has also been suggested that indolyl GSL breakdown products may function as precursors to a class of indole phytoalexins that are induced in Brassica (Rouxel et al., 1989). It is however unclear whether there is any relationship between resistance of fungi to GSL and their ability to cause disease. Although inoculation with L. maculans 
(a)

Fig. 4 Antimicrobial activity of methanol extracted compounds from fertlized $(+\mathrm{S})$ and S-deficient (-S) Brassica napus cv. Express plants. (a) Growth inhibition of Leptosphaeria maculans $(\mathrm{Lm})$, Botrytis cinerea $(\mathrm{Bc})$, Cladosporium ssp. (C. sp) and Penicillium digitatum $(\mathrm{Pd}) .1$ and 2, extracts of plants grown without sulphur fertilization; 3 and 4 , extracts of S-fertilized plants; 2 and 4,10 times diluted compared with 1 and 3 respectively; 5 , water control. The methanol extracted compounds were dried and dissolved in water $(1 \mathrm{ml} / \mathrm{g}$ leaf fresh weight) prior to application. (b) Quantitative analysis of the growth inhibition tests. (c) Inhibitory effect of methanol extracted compounds on the growth of Pseudomonas syringae pv. tomato Botrytis cinerea and Penicillium digitatum. The test organisms were grown and tested in liquid culture in microtitre plates. Quantification was carried out by measurement of the absorbance at $490 \mathrm{~nm}$. Bacterial growth was recorded $24 \mathrm{~h}$ and fungal growth $48 \mathrm{~h}$ after the treatment respectively. Each value is the average of 5 measurements. The experiments were repeated three times with similar results
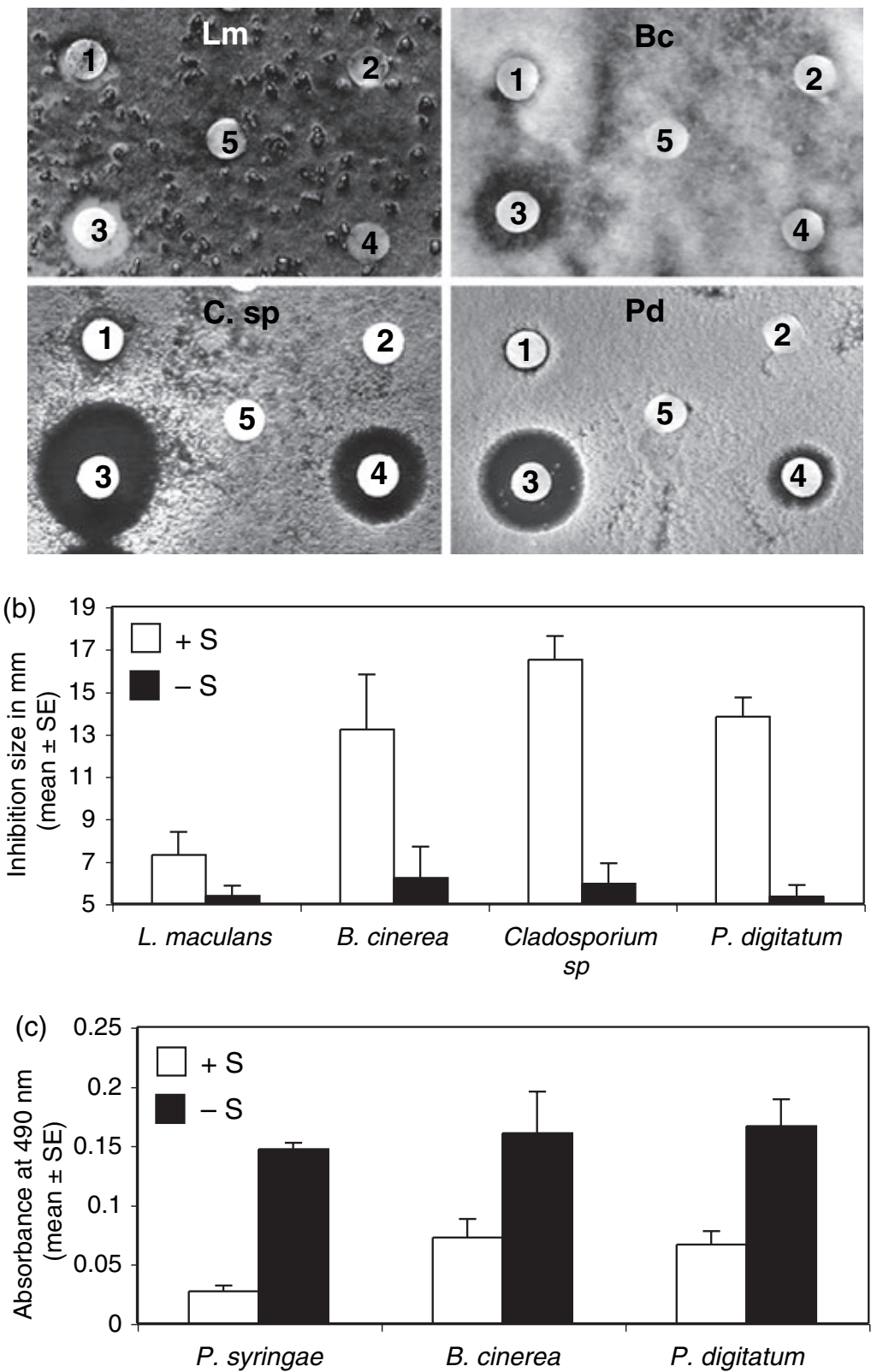

elicited changes in the leaf indolyl-GSL profiles, no correlation was found between the degree of resistance to the fungus and the level of GSL (Wretblad and Dixelius, 2000). The role of GSL in blackleg resistance has previously been studied, but the relevance of these compounds remained unclear. Early studies correlated sinigrin content with resistance to L. maculans (Mithen et al., 1987). High GSL levels have been associated with resistance of oilseed rape and Indian mustard to L. maculans (Mithen and Magrath, 1992) and with resistance of cabbage to $P$. parasitica (Greenhalgh and Mitchell, 1976). However, in studies of crosses of B. napus lines with high and low GSL levels in their leaves, resistance to L. maculans and GSL profiles did not co-segregate (Mithen and Magrath, 1992). Further studies with $B$. napus lines that had contrasting GSL profiles indicated that high levels of GSL are unlikely to confer greater resistance to L. maculans in oilseed rape (Giamoustaris and Mithen, 1997). Furthermore, L. maculans was shown to efficiently degrade the aliphatic GLS sinigrin, progoitrin and gluconapin as well as the aromatic GSL sinalbin (Wu and Meijer, 1999). The high number of different GSL in B. napus makes it difficult to assess the antifungal activity of individual compounds. In addition, the nature of the breakdown products depends on the structure of the GSL, the type of myrosinase present, and other factors, like $\mathrm{pH}$, temperature, metal ion concentrations and protein co-factors (Osbourn, 1996). It is therefore difficult to predict which toxic products a pathogen is likely to encounter simply by assessing the relative amounts of specific GSL present in the host plant. Our tests with a limited number of pure ITCs and the degradation products of sinigrin showed that none of the tested 


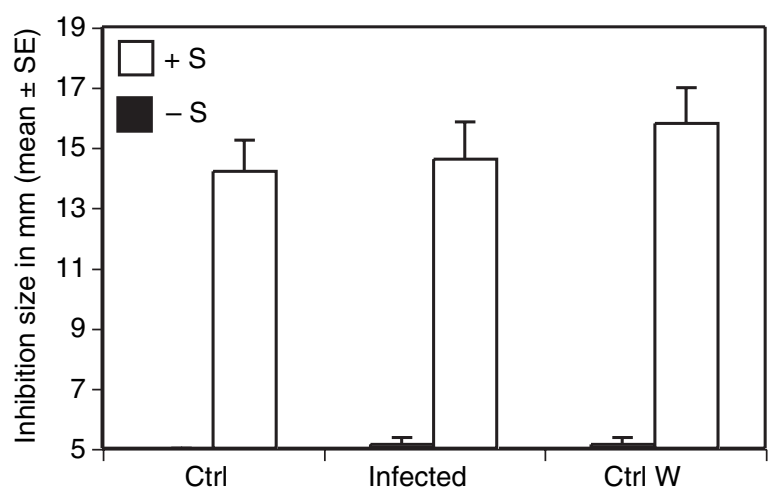

Fig. 5 Methanol extracted compounds of preinoculated plants do not show increased antifungal potential. Growth inhibition tests were performed with Penicillium digitatum. Ctrl, extracts from noninoculated plants; Infected, extracts from plants inoculated with Botrytis cinerea $60 \mathrm{~h}$ prior to extraction; Ctrl W, extracts of non inoculated plants from which the GSL content was analysed (see Table 2 and Fig. 6). Whole leaves were extracted

GSL derived molecules exhibited antifungal activity. Apparently some other compounds possibly including other GSL appear to be responsible for the antifungal activity present in $\mathrm{MeOH}$ extracts of S-fertilized plants. Alternatively, combinations of various GSL might be necessary to inhibit fungal growth.

The same plants and extracts used in this investigation were also exposed to two different insects attacking oilseed rape, the diamond back moth and the cabbage root fly. Both insects prefer for oviposition or feeding S-fertilized plants and extracts or fractions containing GSL or other S-containing secondary metabolites (Marazzi et al., 2004a,b; Marazzi and Städler, 2004). It seems that these herbivores are less affected by the defence mechanisms of S-fertilized plants and have developed detoxification mechanisms against the S-containing secondary metabolites. These insects use in fact the S-containing metabolites to locate and identify plants belonging to their host range.

In conclusion, we have demonstrated that sulphur deficiency increases the disease susceptibility of oilseed rape plants to various pathogens. Our results suggest that a loss of antimicrobial activity in S-deficient plants might contribute to their higher disease susceptibility. The results of the disease resistance tests were

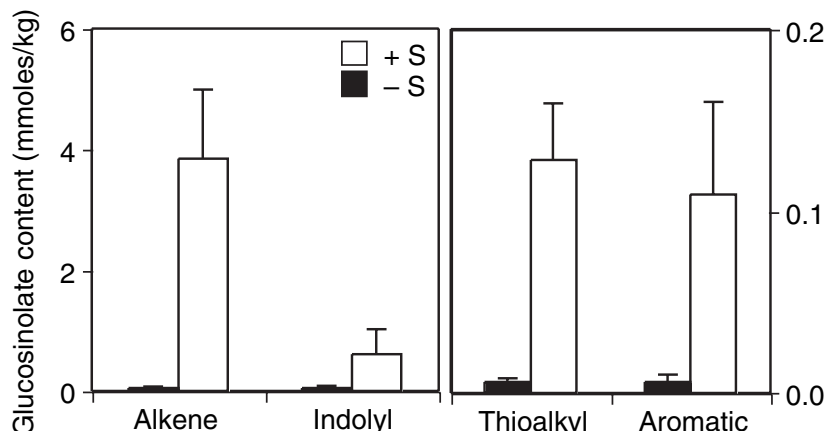

Fig. 6 Quantification of glucosinolate concentration in $\mathrm{MeOH}$ extracts of normal and S-deficient Brassica napus cv. Express. The analysed individual glucosinolates were grouped into four groups according to their chemical features (see Table 2). The content of each group of GSL was stronly reduced in S-deficient plants $(-\mathrm{S})$ compared with control plants $(+\mathrm{S})$. Reduction was $85 \times$ for alkene, $14 \times$ for indolyl, $21 \times$ for thioalkyl and $18 \times$ for aromatic GSL

Table 3

List of isothiocyanates (ITC) tested for antimicrobial activities

ITCs tested in bioassays

Corresponding GSL

Allyl-ITC

Benzyl-ITC

Sinigrin

Ethyl-ITC

Glucotropaeolin

3-methoxyphenyl-ITC

Glucolepidiin

Methyl-ITC

Methoxyphenyl-GSL

Phenylethyl-ITC

Phenyl-ITC

Glucocapparin

Gluconasturtiin

Phenyl-GSL

Ter-butyl-ITC

Butyl-GSL

derived from severely S-starved B. napus plants under conditions that may be rarely found in agricultural soils. However, it is likely that much less severe S-stress in the field still negatively affects the disease resistance of $B$. napus. Even if these effects should appear only minor on an individual plant basis, the effect on a population level could be much more dramatic and has the potential to lead to an increased use of fungicides. To favour sustainable agriculture the sulphur status of S-demanding plants should be monitored in the field in order to increase S-fertilization in case of observed S-deficiency.

\begin{tabular}{lllcr}
\hline Common name & \multicolumn{1}{c}{ Chemical name } & Group & -S & + S \\
\hline Progoitrin & 2-hydroxy-3-butenyl (R) & A & $19 \pm 15$ & $1188 \pm 317$ \\
Sinigrin & 2-propenyl & A & ND & $31 \pm 8$ \\
Napoleiferin & 2-hydroxy-4-pentenyl & A & $24 \pm 18$ & $1182 \pm 361$ \\
Gluconapin & 3-butenyl & A & $1 \pm 1$ & $755 \pm 291$ \\
Glucobrassicanapin & 4-pentenyl & A & ND & $690 \pm 93$ \\
Gluconasturtiin & 2-phenylethyl & B & $6 \pm 4$ & $109 \pm 51$ \\
Glucobrassicin & 3-indolylmethyl & I & $28 \pm 27$ & $371 \pm 238$ \\
Neoglucobrassicin & 1-methoxy-3-indolylmethyl & I & $16 \pm 16$ & $235 \pm 187$ \\
Glucoiberin & 3-methylsulphinylpropyl & T & ND & $4 \pm 2$ \\
Sulphoraphene & 4-methylsulphinyl-3-butenyl & T & $5 \pm 2$ & $65 \pm 17$ \\
Glucoiberverin & 3-methylthiopropyl & T & $1 \pm 1$ & $39 \pm 18$ \\
\hline
\end{tabular}

Table 2

Levels of various glucosinolates measured in leaves from normally grown $(+\mathrm{S})$ and $\mathrm{S}$-deficient $(-\mathrm{S})$ plants of $B$. napus cv. Express

The individual GSL analysed were grouped according to their structural similarities: A, alkene; B, aromatic; I, indolyl and T, thioalkyl. Individual glucosinolate quantification is the mean of five separate extractions. Values are given in $\mu \mathrm{g} / \mathrm{kg}$ of fresh weight plus standard error; ND, not detected. 


\section{Acknowledgements}

We thank Marianne Suter (University of Bern, Switzerland) for the help with the GSH analysis and H. Pfeifer and J.-C. Lavanchy (University of Lausanne, Switzerland) for the total sulphur analysis. We thank Peter Frei, Daniel Gindrat and Katia Gindro (RAC, Nyon, Switzerland) for kindly providing the different strains of Leptosphaeria maculans and Cladosporium sp. This project was part of the COST 829 Action and was financially supported by a grant of the Swiss Federal Office for Education and Science (BBW/OFES-NB. C 98.0099).

\section{References}

Berrocal-Lobo M, Segura A, Moreno M, Lopez G, Garcia-Olmedo F, Molina A. (2002) Snakin-2, an antimicrobial peptide from potato whose gene is locally induced by wounding and responds to pathogen infection. Plant Physiol 128:951-961.

Blake-Kalff MMA, Harrison KR, Hawkesford MJ, Zhao FJ, McGrath SP. (1998) Distribution of sulfur within oilseed rape leaves in response to sulfur deficiency during vegetative growth. Plant Physiol 118:1337-1344.

Dämmgen U, Walker K, Grünhage L, Jäger H-L. The atmospheric sulfur cycle. In: Schnug E (ed.), Sulfur in Agroecosystems, Dordrecht, Kluwer Academic Publishers, 1998. pp. 75-114.

Davidson RM, Goss RL. (1972) Effects of P, S, N, lime, chlordane, and fungicides on ophiobolus patch disease of turf. Plant Dis Report 56:565-567.

Eriksen J, Mortensen JV. (1999) Soil sulphur status following longterm annual application of animal manure and mineral fertilizers. Biol Fertil Soils 28:416-421.

Giamoustaris A, Mithen RF. (1997) Glucosinolates and disease resistance in oilseed rape (Brassica napus ssp oleifera). Plant Pathol 46:271-275.

Graner G, Hamberg M, Meijer J. (2003) Screening of oxylipins for control of oilseed rape (Brassica napus) fungal pathogens. Phytochemistry 63:89-95.

Greenhalgh JR, Mitchell ND. (1976) Involvement of flavor volatiles in resistance to downy mildew of wild and cultivated forms of Brassica oleracea. New Phytologist 77:391-398.

Griffiths D, Deighton N, Birch A, Patrian B, Baur R, Städler E. (2001) Identification of glucosinolates on the leaf surface of plants from the Cruciferae and other closely related species. Phytochemistry 57:693-700.

Hammerschmidt R, Dann EK. The role of phytoalexins in plant protection. In Chadwick DJ, Goode JA (eds), Insect-Plant Interactions and Induced Plant Defence, Chichester, J. Wiley and Sons, 1999. pp. 175-191.

Hammond KE, Lewis BG. (1987) The establishment of systemic infection in leaves of oilseed rape by Leptosphaeria maculans. Plant Pathol 36:135-147.

Hammond KE, Lewis BG, Musa TM. (1985) A systemic pathway in the infection of oilseed rape plants by Leptosphaeria maculans. Plant Pathol 34:557-565.

Haneklaus S, Schnug E. (1992) Macroscopic symptomatology of sulfur deficiency symptoms in Brassica napus. Phyton-Ann Rei Botanicae 32:55-58.

Harms K, von Ballmoos P, Brunold C, Hoefgen R, Hesse H. (2000) Expression of a bacterial serine acetyltransferase in transgenic potato plants leads to increased levels of cysteine and glutathione. Plant J 22:335-343.

Harper FR, Berkenkamp B. (1975) Revised growth-stage key for Brassica campestris and B. napus. Can J Plant Sci 55:657-658.

Hartill WFT, Sutton PG. (1980) Inhibition of germination of Mycosphaerella brassicicola ascospores on young cabbage and cauliflower leaves. Ann Appl Biol 96:153-161.

Hashem FA, Saleh MM. (1999) Antimicrobial components of some Cruciferae plants (Diplotaxis harra Forsk. and Erucaria microcarpa Boiss.). Phytother Res 13:329-332.

Hell R. (1997) Molecular physiology of plant sulfur metabolism. Planta 202:138-148.

Hoagland DR, Martin JC. (1950) Availability of potassium to crops in relation to replaceable and nonreplaceable potassium and to effects of cropping and organic matter. Soil Sci Soc Am Proc 15:272-278.
Howlett BJ, Idnurm A, Pedras MSC. (2001) Leptosphaeria maculans, the causal agent of blackleg disease of Brassicas. Fungal Genet Biol 33:1-14.

Leustek T, Martin MN, Bick JA, Davies JP. (2000) Pathways and regulation of sulfur metabolism revealed through molecular and genetic studies. Annu Rev Plant Physiol Plant Mol Biol 51:141165.

MacFarlane HH. Plant host-pathogen index to volumes 1-40 (19221961). In: C. M. Institute (ed.), Review of Applied Mycology, Kew, C. M. Institute, 1968.

Man in't Veld WA, de Cock AWAM, Ilieva E, Lévesque CA. (2002) Gene flow analysis of Phytophthora porri reveals a new species: Phytophthora brassicae sp. nov. Eur J Plant Pathol 108:51-62.

Manici LM, Lazzeri L, Palmieri S. (1997) In vitro fungitoxic activity of some glucosinolates and their enzyme-derived products toward plant pathogenic fungi. J Agri Food Chem 45:2768-2773.

Marazzi C, Städler E. (2004) Influence of plant sulphur nutrition on oviposition and larval performance of diamondback moth. Entomol Exp Appl 111:225-232.

Marazzi C, Patrian B, Städler E. (2004a) Secondary metabolites of the leaf surface affected by sulphur fertilisation and perceived by the diamondback moth. Chemoecology 14:81-86.

Marazzi C, Patrian B, Städler E. (2004b) Secondary metabolites of the leaf surface affected by sulphur fertilisation and perceived by the cabbage root fly. Chemoecology 14:87-94.

Mari M, Iori R, Leoni O, Marchi A. (1993) In-vitro activity of glucosinolate-derived isothiocyanates against postharvest fruit pathogens. Ann Appl Biol 123:155-164.

Milford GFJ, Fieldsend JK, Porter AJR, Rawlinson CJ, Evans EJ, Bilsborrow $\mathrm{P}$. Changes in glucosinolate concentrations during the vegetative growth of single- and double-low cultivars of winter oilseed rape. ASP Appl Biol 23:83-90.

Mithen RF, Magrath R. (1992) Glucosinolates and resistance to Leptosphaeria maculans in wild and cultivated Brassica species. Plant Breed 108:60-68.

Mithen RF, Lewis BG, Fenwick GR. (1986) In vitro activity of glucosinolates and their products against Leptosphaeria maculans. Trans Br Mycol Soc 87:433-440.

Mithen RF, Lewis BG, Heaney RK, Fenwick GR. (1987) Resistance of leaves of Brassica species to Leptosphaeria maculans. Transac Br Mycol Soc 88:525-531.

Nikiforova V, Freitag J, Kempa S, Adamik M, Hesse H, Hoefgen R. (2003) Transcriptome analysis of sulfur depletion in Arabidopsis thaliana: interlacing of biosynthetic pathways provides response specificity. Plant J 33:633-650.

Osbourn AE. (1996) Preformed antimicrobial compounds and plant defense against fungal attack. Plant Cell 8:1821-1831.

Pedras MSC, Okanga FI, Zaharia IL, Khan AQ. (2000) Phytoalexins from crucifers: synthesis, biosynthesis, and biotransformation. Phytochemistry 53:161-176.

Pezet R, Zuccaroni P, Beffa T. (1986) Soufre élémentaire:mode d'action fongicide et rôle chez les plantes. La Défense des Végétaux 239:3-16.

Rouxel T, Sarniguet A, Kollmann A, Bousquet JF. (1989) Accumulation of a phytoalexin in Brassica spp in relation to a hypersensitive reaction to Leptosphaeria maculans. Physiol Mol Plant Pathol 34:507-517.

Saito K. (2000) Regulation of sulfate transport and synthesis of sulfur- containing amino acids. Curr Opin Plant Biol 3:188-195.

Schnug E. Significance of sulphur for the nutritional and technological quality of domesticated plants. In: Cram WJ, De Kok LJ, Stulen I, Brunold C, Leiden RH (eds), Sulfur Metabolismus in Higher Plants - Molecular, Ecophysiological and Nutritional Aspects, The Netherlands, Backhuys Publishers, 1996.

Schnug E, Haneklaus S. (1992) Sulfur and light-element determination in plant-material by X-ray fluorescence spectroscopy. Phyton-Annales Rei Botanicae 32:123-126. pp. 109-130.

Si-Ammour A, Mauch-Mani B, Mauch F. (2003) Quantification of induced resistance against Phytophthora species expressing GFP as a vital marker: beta-aminobutyric acid but not BTH protects potato and Arabidopsis from infection. Mol Plant Pathol 4:237-248. 
Tierens K, Thomma BPH, Brouwer M et al. (2001) Study of the role of antimicrobial glucosinolate-derived isothiocyanates in resistance of arabidopsis to microbial pathogens. Plant Physiol 125:1688-1699.

Vignutelli A, Wasternack C, Apel K, Bohlmann H. (1998) Systemic and local induction of an Arabidopsis thionin gene by wounding and pathogens. Plant J 14:285-295.

Williams JS, Cooper RM. (2003) Elemental sulphur is produced by diverse plant families as a component of defence against fungal and bacterial pathogens. Physiol Mol Plant Pathol 63:3-16.

Williams JS, Cooper RM. (2004) The oldest fungicide and the newes phytoalexin - a reappraisal of the fungitoxicity of elemental sulphur. Plant Pathol 53:263-279.
Wretblad S, Dixelius C. (2000) B-genome derived resistance to Leptosphaeria maculans in near isogenic Brassica napus lines is independent of glucosinolate profile. Physiol Plant 110:461-468.

$\mathrm{Wu}$ X-M, Meijer J. In vitro degradation of intact glucosinolates by phytophathogenic fungi of Brassica. In: Proceedings of the 10th International Rapeseed Congress, Canberra, 1999.

Zhao FJ, Bilsborrow PE, Evans EJ, McGrath SP. (1997) Nitrogen to sulfur ratio in rapeseed and in rapeseed protein and its use in diagnosing sulfur deficiency. J Plant Nutri 20:549-558.

Zimmerli L, Metraux J-P, Mauch-Mani B. (2001) $\beta$-aminobutyric acid-induced protection of Arabidopsis against the necrotrophic fungus Botrytis cinerea. Plant Physiol 126:517-523. 